\title{
EIGHTEENTH CENTURY PHARMACY AT ST. GEORGE'S HOSPITAL, LONDON
}

by

JOHN K. GRELLIN

St. George's Hospital was founded in 1733 , as a result of dissension among the governors of Westminster Infirmary, when it was decided to find more suitable buildings. Lanesborough House, near Hyde Park and some premises in Castle Lane were suggested. A lease to the former was obtained by a few governors, in trust for a new society, this becoming St. George's, while the majority accepted the Castle Lane property.

Not unexpectedly the magnitude of this split led to the differences being aired elsewhere than around the Board Room table. The hospital's point of view was put forward in An Account of the Occasion and Manner of Erecting a Hospital at Lanesborough House, near Hyde Park Corner. Published by Order of the General Board of Governors, there, Wednesday, February the 6 th, $1733,{ }^{* 1}$ which has one paragraph lucidly describing the organization of the pharmaceutical service:

They have in their house an apothecary and a complete shop, and all the physicians, surgeons, apothecaries, chymists and druggists are a committee to buy the drugs and other materials for making the medicines there; under whose inspection all the medicines are made, and the following apothecaries, viz., John Warren and Daniel Graham, Esqrs., Apothecaries to His Majesty's Household; Mr. Isaac Rand, Botany Professor of Chelsea College; Mr. John Clarke, Mr. Andrew Mitchell, Mr. Thomas Graham and Mr. James Fraser attend by rotation as visitors to see them duly dispensed according to the prescriptions of the physicians.?

It is thus clear that the efficient organization of the Pharmacy department was considered of utmost importance. Notable, in this regard, is the emphasis on supervision of the apothecary and his shop, which, as will be seen from the minutes, was fully implemented although apparently relaxed for the two apothecaries of competence and long standing. Two main reasons account for the rigorous supervision; firstly, the hospital was a charitable institution and economy was, of necessity, always uppermost in the thoughts of the governors. Secondly, the governors maintained strict rules and regulations for the staff, while the hospital physicians (and towards the end of the century the surgeons, to a lesser degree) possessed the authority in matters relating to drugs and medicines.

This last factor is a measure of the inferior status, in all medical matters, of the hospital apothecary to that of his counterpart, the physician. His indispensable value to the hospital, however, was his residence, and he, along with the surgeon's apprentice (house surgeon), constituted the resident 'medical' staff.

* The reformed Gregorian Calendar was not adopted until 1752, and dates prior to this have been left in the old style. 


\section{Fohn K. Crellin}

This importance led to great care in choosing the apothecary and it is illustrative to introduce the various apothecaries of the hospital in order to provide part of the background that necessitated, at times, certain rules and changes. Also, the great care in their selection, in addition to probationary periods, did not always lead to satisfaction-indicative of the disparity among eighteenth century apothecaries.

The onus on the resident apothecary was especially heavy during the teething stages of the new hospital and might well be reflected in the early difficulties of finding a satisfactory person. The first apothecary was a Mr. Aldridge, first mentioned at the third Board meeting (26 October 1733 ) when, upon the recommendation of $\mathrm{Mr}$. John Clarke, it was 'resolved that Mr. Aldridge be taken in as an apothecary to the infirmary at Lanesborough House on tryall or probation without expense'.* This 'tryall or probation' was hardly onerous as the hospital was not opened to patients until I January, his trial period then being increased for a further three months. The minutes for 7 December 1733 record Aldridge's efforts to become apothecary. 'Mr. Aldridge the apothecary, for the satisfaction of this Board proposed Mr. Hopkins, a cloth worker in Maxfeild Street Goodman's Feilds, to be security with him in the sum of $£ 200$ for his good behaviour as an apothecary to this hospitall.' Two hundred pounds was a remarkably large sum and no later apothecary paid a security. It is probable that Aldridge was the same person discharged from Westminster Infirmary in 1733 , following a dispute with a physician. ${ }^{3}$ Unfortunately he fared no better at St. George's; on 29 January 1734, Aldridge was the target of a visitor's $\dagger$ complaint whereupon he 'informed the Board that the physicians had ordered the patient complaining an electuary that was not in the shop and he could not procure it till last Fryday, which was the occasion of the complaint'. This and previous misdemeanours resulted in his discharge (12 March 1734).

The election of the second apothecary, John Cuhn, set the pattern for subsequent ones. The post was advertised in the newspapers and a 'medical' committee formed of the physicians, surgeons and apothecaries who were governors-this included the hospital physicians and surgeons-'to examine into the characters and qualifications of the apothecaries who offer themselves to serve this house in that station'. Such committees, till the turn of the century, upheld the practice of meetings in coffee houses, where the candidates were interviewed. The committee's deliberations were reported to a Special Court, and in the case of Cuhn, he, being the only person put forward, was elected. He was no more satisfactory than Aldridge and we read (on ro October I 735), 'it being the opinion of this Board that Mr. Cuhn ... is not equall to the business of this house'. This dissatisfaction may have been a contributing reason for it being considered, at the same meeting, 'necessary that a surgeon should constantly reside in the house and that one of the apprentices of the surgeons ...

* The minutes are quoted verbatim throughout this paper apart from omitting a number of capital letters.

t It was the practice for two governors to visit the hospital on one day per week as 'visitors' and report to the following weekly Board. This is in addition to the visits of the 'visiting apothecaries'. 


\section{Eighteenth Century Pharmacy at St. George's Hospital, London}

do for the future constantly reside in the house'. In contrast to this early appointment, there was no house surgeon at Guy's or St. Thomas's hospitals till $\mathrm{I} 792.4$

On 12 November 1735, upon the recommendation of the committee, Cliffe was 'admitted to officiate with Mr. Guhn ... till next General Board'. Gliffe's appointment, on Cuhn's dismissal, was confirmed when the Board accepted the committee's preference of Cliffe over a Mr. Church. It is important to realize that the 'medical' committee's support of a particular candidate did not automatically lead to his appointment, this being, as indicated, on election by the governors. As the century progressed competition for the post grew keener with an increase in canvassing among the governors. Though possibly not so intensive as by physicians for appointments, it presented no little concern. It was reported (6 February I 793) that 'Mr. Pearson at the desire of Dr. Halifax ... reported to the Board that Mr. Harding one of the candidates for the office of apothecary had in the course of his canvas made an improper and unwarrantable use of his name whereby it is apprehended many governors had promised him their votes'. A second reference to canvassing, at the end of $180 \mathrm{or}$, gives a clear picture. The committee was a safeguard that candidates had a satisfactory character and adequate qualifications and experience to fulfil the post.

The governors are particularly requested ... not to engage their votes for the approaching election of an apothecary till the merits of the candidates have been duly examined and a report made by the physicians according as has been usual on former occasions.

Cliffe soon resigned owing to ill health (24 November I 736), the vacant position being advertised. Charles Treffrey was the only candidate recommended by the committee, but the Court, with past experiences in mind, was wary and they 'ordered that Charles Treffrey be taken as an apothecary upon tryall till the next Quarterly Board and in case he behaves well to be elected and that the thanks of this Board be given to the said committee for their care and diligence in this affair' (14 January 1737 ). Six months in fact passed before he was elected. His long tenure of office, till his death in $\mathrm{r} 757$, at last gave stability to the shop and he served without registered complaint.

His passing occasioned some difficulty in the running of the shop before another apothecary could be found and it was ordered 'that the supply ... be under the direction of the physicians ... a and that Mr. Edgar [probably a physician's pupil] be desired to give his assistance as often as he can in the apothecary's shop'.

The names of two 'well qualified' candidates were given by the committee for the choice of the Special General Court, and the election brought an impressive number of governors to vote. William Dampier was elected by eighty-eight votes to his opponent's thirty-four. He served the hospital for thirty-six years without dissatisfaction from the Board though it will be noted below that his age eventually cast many of his duties on to his staff. Dampier's death was reported on 9 January 1793 , and the usual procedures for obtaining a new apothecary set in motion. Three 'qualified' candidates were submitted to 


\section{John K. Crellin}

the Special Court, the committee themselves supporting the ultimately elected Burton Browne, the voting being Browne sixty-one, Harding twenty-eight (his underhand canvassing has been mentioned) and Hawkins fourteen.

Browne resigned on Io February I 796 after a satisfactory term of office-a motion, on the instigation of the physicians, was passed thanking him for his services. A gesture reflecting the close liaison between apothecary and physician. Even so, the advertisement of the vacant position was of a far more stipulating nature than any published previously. It referred to the candidate's age 'to be about forty years' and his being a 'single man of fair character and who must produce testimonials of [his] character and qualification'. The 'medical' committee also changed in character consisting solely of the hospital physicians and surgeons, a measure of the greater responsibility they had assumed, by this time, in the general running of the hospital. For many years they had been almost the sole governors attending the weekly Board meetings. In addition, their greater say in vetting candidates for resident apothecary was desirable in that they required someone they could agreeably work with.

Six candidates were suggested for the Court's consideration and a Mr. Butler recommended. Before the election, however, convincing statements supporting the candidature of $\mathrm{Mr}$. Hawkins were read to the governors. The heavy voting was Hawkins ninety-three, Butler thirty and Prosser two.

Richard Hawkins died on 16 September 1798 , the third apothecary to die while in office. The only variation from previous times in filling the post was that information ... of such vacancy [was also given] to those druggists who serve the charity'. This shows an awareness of the changing status of the apothecary and druggist although at St. George's there was no increase in the former's medical duties and certainly it hadn't been previously envisaged that a druggist might be suitable. Of the eight candidates put forward, for some unexplained reason all withdrew except Kelly, who was duly elected.

This was unfortunate for the hospital for he was both incompetent and of a quarrelsome disposition. He tendered his resignation on I I November I8o I, only to later try to retract it. This was refused, a special committee having been set up to inquire into his work. The committee was of the

unanimous opinion that Mr. Kelly was very defective in those branches of knowledge which were particularly required of him and that after a trial of three years during which he had repeatedly been informed that the Board were by no means satisfied with his service; he made no improvement and that in justice to the hospital they were reduced to the disagreeable necessity of taking measures to getting another person.

The assistant apothecary, Prosser, succeeded Kelly being elected after a trial period as acting apothecary. Prosser, it would seem, merited his new position for it had been unanimously resolved on a previous occasion (Io February 1797) 'that the apothecary's assistant Mr. Prosser do have an additional gratuity of three pounds for the year 1796 as a reward for his attention to and good conduct in his situation'.

The assistance to the apothecary was the matter for much thought in the 


\section{Eighteenth Century Pharmacy at St. George's Hospital, London}

early years. A committee of the apothecaries, who were governors, was formed on 24 April 1 734, ostensibly to settle 'the care and custody of the medicines of this house', but it soon gathered other duties connected with the shop. On 14 January 1736 it was referred to them 'to consider how farr a journeyman apothecary is necessary and in what manner he is to act'. No more is heard of this, the situation contrasting with St. Bartholomew's where, in 1748 , their apothecary was allowed $£ 30$ for a journeyman. ${ }^{5}$ In fact the number of apothecary's staff-a labourer and apothecary's man (assistant)-remained unchanged at St. George's throughout the century.

The first staff problem arose from the visiting apothecaries' query about 'the use of an underapothecary' (2 I December I 737). The Quarterly Court 'resolved that the underapothecary be absolutely a servant to and under the direction of Mr. Treffrey'. This did not satisfy Hutton, then the assistant apothecary, who resigned but was accorded the thanks of the Board for his services. He was probably not content with the menial tasks and wished to usurp some of the apothecary's duties, a situation the Board could not tolerate. Under Dampier, however, this did come about and towards the end of the seventeen hundreds the post of assistant apothecary achieved worthy status. Shortly after the turn of the century the position was vacant and for the first time the vacancy was advertised. With respect to the situation that developed under Dampier; the minutes of 29 August $\mathrm{I} 798$ afford an insight into the rigid interpretation of the hospital laws, necessary to ensure the hospital's efficiency.

It being apprehended that according to the laws of this hospital the business in the department of the apothecary ought to done by the apothecary himself and his pupil excepting the ordinary menial business of the shop-but as on account of the infirmities from age of one of the late apothecaries Mr. Dampier, the assistant servant of the shop and elaboratory had conducted part of the business of the apothecary without the permission of the Board which practice had continued to a certain degree up to the present time and it being imagined that a custom continuing for so long a time may finally establish by usage an unnecessary office.

Returning to the Quarterly Court's ruling on the underapothecary, they at the same time requested the committee of apothecaries to 'consider more fully the use and business of the underapothecary'. Isaac Rand, F.R.S., reported (1o February 1 737) from the committee, a perceptive, if for the time somewhat ideal, summing up of the position.

It was the [committee's] unanimous opinion that the only way to lessen the great expense ... for medicines is to have a more effectual assistant, that is, a man who understands pharmacy and is able and willing to labour hard and to apply entirely to the business of the shop and elaboratory and likewise to be absolutely under the direction of the apothecary by this means they ... might make all their gallenicall medicines at home which are bought ready made at a high price.

No further mention is made of this report and it is certain that no prior experience was in fact required of the assistant apothecaries. The turnover of new assistants was considerable though not of the same order as that of the labourers. It is 
to be remembered that gin drinking was rife in London for much of the eighteenth century and this is mirrored in the many changes of labouring and nursing staff, most markedly up to 1770 . Drunkenness had repercussions at least once in the shop, for in July I 790, the apothecary's man was the cause of a complaint by the physicians. He being 'in that state [of drunkenness] committed a mistake that endangered the life of a patient'. Owing to his previous excellent service he was given a reprieve depending on his 'perfect sobriety and future good behaviour'.

An effort to improve the efficiency of the department was made on 14 June 1738 when it was resolved that the next Quarterly Board 'consider of allowing the apothecary [as a further encouragement] a pupill in lieu of his yearly gratuity'. This was ultimately refused. Even so the practice (not recorded) of having a pupil must have commenced soon after this as on 27 October 1756 , there is a reference to the meals for the apothecary's pupil. Also in the same minutes it is stated that when a new apothecary's pupil or a house surgeon is

presented to the Board to hear the rules for his conduct in the House, that at the same time the matron and two senior nurses be called to the Board and that in their presence the pupill be charged to behave towards the matron, nurses and other servants with decency and civility.

This injunction was the result of previous differences. No names of pupils occur until $26 \mathrm{January} \mathrm{I} 780$, it then being reported that ' $\mathrm{Mr}$. Thomkinson apothecary's pupil paid $£_{25}$ for one year's board'. This entry, in all likelihood, is the result of a general tightening up of administration due to the financial plight of the hospital. In this connexion it is to be noted that from 18 February 1780 , the $£ 25$ was an increase from $£$ io. The pupil's cost of board was a ready source of income and it was later further increased to $£ 35$ ( 1 797). It was the practice for an apprentice to undergo part of his seven years' apprenticeship in a hospital and it is seen from the minutes of 6 November I 799, that St. George's pupils had previously undertaken part of their training:

Dr. Robertson Barclay moved that the rule requiring that the pupil should have previously served an apprenticeship be suspended for this nomination only. No person having offered as pupil who possessed that qualification.

This was agreed to and on I I December I 799 it was decided that 'Mr. Stuart be received as apprentice ... to the hospital for three years upon the payment of two hundred guineas to the hospital. One hundred guineas as apprentice fee [paid in yearly instalments] to the apothecary and one hundred guineas for the expenses of the Board.' Stuart's indentures were cancelled and burnt (1o February 1802) before the end of three years, retribution for his misconduct.

One more pupil was hired before a revaluation of the pharmacy staff by a committee of the hospital physicians and surgeons. Their conclusion was that owing to 'the inefficiency of such assistance, that the office of pupil to apothecary is unnecessary and that the same will be discontinued after the expiration of the term of the present pupil'. 


\section{Hospital Life and Non-Pharmaceutical Duties}

Before considering the work of the house apothecary in regards to his pharmaceutical and large number of more general duties, it will be of interest to look at the glimpses and insights, from the minutes, into his life and living conditions within the hospital. As hospital apothecary his time continuously revolved around the hospital. Among the first rules relating to the apothecary, noted on 16 November I 733, we read 'that he do not presume to practice as an apothecary out of the house or do any other business than the business of this house'. This was a common stipulation for hospital apothecaries though St. Bartholomew's apothecary, not being resident till 1747 , ran an outside drug business until that time. ${ }^{5}$ The regulation of his hours, soon after the hospital opened, must have anyway effectively precluded outside business - 'that the house apothecary be never absent without leave from one of the visitors' (6 February I 733). This rule was repeated on 9 October I 734, probably a reprimand for the erring Aldridge. Also the supervision was considerably increased in that each leave was to be in writing expressing the time from which and the time to which he desired leave of absence and be signed by such visitor and entered in the visitor's memorandum book'. Treffrey was the only apothecary to have a regular annual holiday 'in the country'. Difficulty was perhaps occasioned in that the apothecary had to find a suitable person to stand in for him.

Wages were not high and lower than a number of other London hospitals. Until I4 January 179 I the salary remained at $£ 20$ p.a. with a gratuity of $£ 4^{\circ}$ p.a. It was the custom to give to every officer and servant a gratuity 'to encourage their diligence and application in their respective stations and not to be looked upon as additional wages'. Indeed it was not uncommon for a nurse or labourer to lose all or part of their gratuity for relapses such as excessive drinking and being absent without leave. On I4 January I 79I, the salary scale was changed to $£ 40$ p.a. and $£ 20$ gratuity-the total yearly income remaining as before. From 1766 both the apothecary and the clerk received an extra twelve guineas p.a. (increased to fifteen guineas in I 79I) in lieu of coals, candles, washing and lamp spirits.

Living conditions for the apothecary were reasonably comfortable. He, along with the other officers, had their meals separate from the 'inferior servants' and the first hospital porter was only allowed to dine with the apothecary and matron on account of the latter being his wife! (June I 737). Complaints concerning the food were made in 1756 ( 27 October), and in consequence the Board considered 'the present regulation of the family table and diet and came to certain regulations'. Among these, we learn that the matron was given 'liberty to vary the dinner on Sundays and according to her own discretion .... and that when there is salt meat, she provide a bit of fresh meat ... that the matron give to the apothecary, house surgeon, the clerk and the apothecary's pupil a bit of fresh butter every day to breakfast if they desire it'. This better fare later received setbacks, as did the food of most of the population during the Napoleonic wars. From a number of economy measures on food there is, for instance, that of 


\section{John K. Crellin}

I 7 December I80o: 'the nurses and other servants be allowed daily $\frac{1}{2}$ lb bread with an addition of rice and that on two days each week ... two white or corned herrings and I lb potatoes'. Prosser, as assistant apothecary, escaped this particular menu since from I May I 799, he had been allowed to join the family in the Board room for meals.

The apothecary had his living quarters with other resident staff in the house adjoining the hospital. The minutes mention occasional additions to his rooms as sanctioned by the Board, for example, a stove grate, two pairs of sheets and a tea kettle. Details of the furniture were, however, concisely given when apothecaries Browne (who had been allowed fifteen guineas for more furniture) and Kelly had to sign itemized lists, to witness the hospital furniture in their rooms. Kelly's furniture on 20 March I 799 was

Bed Room: A fourpost bedstead, a window curtain to match, bedside carpet, feather bed, bolster, two pillows, two mattress's, three blankets and cotton counterpain, two painted chairs, chest of drawers, night table, two pairs of sheets, two pairs of pillow cases.

Dining Room: Bath, stove fender and fire iron, carpet, six mahogany chairs brass nailed, one dining table, one pembroke table, two window curtains.

Finally, one important law, in the eyes of the Board, but which not infrequently lapsed during the century, was that it was required that the staff, especially apothecary, matron and clerk worship in the hospital every Sunday. It was hoped that this would set an example to the patients, much emphasis always being placed on their 'spiritual health'.

The day to day running of the hospital was largely in the hands of the matron and the apothecary, but the extent of their authority was carefully regulated by the hospital laws. Matron's duties were wide, entailing organizing provisions, supervision of the 'inferior servants' and the patients. It was nevertheless the apothecary and to a small extent the house surgeon, who were primarily concerned with supervision of the patients and their nursing. Early in the minutes, on 20 February 1733 , it is written that the physician was 'to leave a list of patients with the apothecary to be given by him into the Board next day ... and each physician to visit any of his respective patients ... as often as he shall think it necessary or shall have notice of such necessity sent him by the apothecary'. The last direction is illustrative of the openings whereby a number of apothecaries in many hospitals were in a position to become veritable resident medical officers. The apothecary was also to see that the correct diet was given to the patients.

That the apothecary shall fix one of the ticketts [naming the prescribed diet] on each patient's bed according to the prescription of his physician and that he shall take care the ticketts so fixed do exactly correspond with the physician's book and shall give a regular list thereof to the matron each prescription day (9 October 1734 ).

Moving patients within the hospital was another task and on 20 November I 734 it was directed 'that the matron do (upon notice from the apothecary of any patient casually falling into salivation) cause such patient to be immediately 


\section{Eighteenth Century Pharmacy at St. George's Hospital, London}

removed into the salivatory ward'. Again in the early $\mathrm{I} 750 \mathrm{O}$, it was 'ordered that the patients be not removed from one bed to another but by the direction of one of the physicians, surgeons or the apothecary or in case of necessity in their absence the matron'. If such insistence is quaint compared to present day practice it is to be noted that patients were not confined to their beds but by disability. Two regulations indicate the difficulties the eighteenth century resident hospital staff contended with in having patients.

That all patients shall behave themselves decently in the house, and, if able shall attend public prayers; and shall not swear curse, or use abusive language, quarrel, filch or drink immoderately or talk or eat immodestly, on pain of expulsion.

That no outpatient be absent, nor any in-patient be out of doors, on Saturday the general visiting day.

Much must have fallen on the apothecary and an example of his surveillance is shown when he notified the Board of the 'riotous behaviour' of two patients on Christmas Day I 782, resulting in their discharge. The apothecary could give permission for a patient to have leave from the hospital (this was rescinded in Kelly's time due to his incompetence) and he also supervised some of the miscellaneous work performed in the hospital by patients. On 27 May I 74I it was ordered 'that the pallisades and rails before the front of the hospital be painted by the patients that are able and the colours bought by the apothecary'; more mundanely, 'Mr. Treffrey was to order all such patients as are able from time to time to assist the messenger and other servants in emptying the bath and boghouse' (28 June 1 738).

During the century his duties changed but little. Occasionally a new duty reflected the financial difficulties of the hospital as when, 'the expense of shaving having of late been considerable, ordered that no person be in future shaved but by order of the apothecary or house surgeon' (24 February 1790). Or, when in order to reduce the hospital expenses the number of beds was reduced to I50, 'that the apothecary be acquainted therewith, and be permitted to dispose of them [i.e. the surplus beds] . . . as he shall judge most expedient'.

A further interesting task, epitomizing the flexible nature of the apothecary's work, is seen in $I 793$. It was arranged

that the house apothecary and house surgeon have permission to attend at the house erected on the side of the Serpentine River in Hyde Park for the purpose of restoring animation to persons taken out . . . apparently drowned whenever Mr. Jackson of Knightsbridge . . . be absent ... and their own business will allow them.

Lastly, a number of jobs fell to the apothecary's staff such as carrying coals and cleaning the dead house. The unpleasant nature of this last fatigue was recognized in the size of the gratuities given.

\section{Pharmaceutical Organization}

The first mention of the apothecary's shop is in the minutes of the first General Board meeting held on 19 October 1 733. It was 


\section{John K. Crellin}

resolved that a committee be appointed to fix, fitt up and furnish the apothecary's shop, with such medicines and other utensils as they shall judge necessary for present use and that $\mathbf{M r}$. Serjeant Dickens, Mr. Rand, Mr. Clarke and Mr. James Fraser be the said committee.

Subsequently, twenty guineas were paid to a Mr. Hope for the apothecary's shop and other bills for utensils paid. A few references in later minutes bring to light some of the equipment used in the shop and the laboratory, for instance, a pestle and mortar ( $£$ II $95.6 d$. in 1737 ) and a new still and worm tub for $£ 262$ s. $6 d$. in 1783 .

Rules regarding the pharmaceutical duties of the apothecary were carefully drawn up, and though on paper, the invigilation rather tended to place him in the rôle of technician, he in practice had ample scope for his skills.

That he take care of the shop, utensils and medicines and see that none of them be spoiled or imbezilled. That the physic be made up according to the prescription of the doctors and be dispensed without loss of time. N.B. the physicians are desired to find a further check upon the apothecary ( 16 November 1733 ).

This further check fell on the visiting apothecaries, who will be considered more fully below. Another regulation regarding dispensing practice was made on I5 May I 734, it being 'ordered that the apothecary of this house do boil all physicall preparations and the cooke shall not interfere'. This rather unusual piece of legislation probably resulted from trouble between apothecary and cook. Whatever the case the latter was discharged two weeks later. The episode is an amusing echo of Bulleyn's admonition to the apothecary in his Bulwarke of Defense ( 1562$)$, 'that he doe remember his office, is only to be the physician's coke'.

That adequate directions were given with medicaments supplied to patients was rightly emphasized in two early regulations.

Ordered that the house apothecary do always keep proper quantities of pills powders electuaryes and whatsoever can be conveniently so kept ready to be delivered to patients as they are directed by the physicians with proper directions upon oath (6 February 1 733).

\section{The last point was elaborated later when it was}

resolved that the apothecary do not presume to deliver any druggs or medicines to out or in-patients without particular directions in writing affixed thereto how the same are to be taken or applied (28 January 1735 ).

The in-patients (if possible) as well as the out-patients presented themselves at the shop for their medicines, etc., although the onus was on the apothecary and nurses to see that the former had their treatment. The affixing of a written label must have often been a matter of form for many illiterate indigents must have found themselves at the charity hospital. The problem arose again in 1793 when the physicians were asked their opinion concerning 'the mode of delivery to outpatients'. Their reply prompted the order 'that in future [when] medicines be given to out-patients, [then] printed directions do accompany each medicine'.

$$
336
$$




\section{Eighteenth Century Pharmacy at St. George's Hospital, London}

The occasional printer's bill for the shop suggests that this practice was not altogether new.

The price of containers for medicaments often caused consternation and the following ruling was enacted:

that the house at first supply the patient with potts and phialls in the apothecary's shop and the patients be obliged to bring the same as they come for new medicines on pain of being sent back for the same and medicines refused till they bring the same (6 February 1733).

This was rigidly followed, the bill for 'potts and phialls' remained fairly constant for a considerable time at around $£ 30$ p.a. Even so, when the expenses of the shop were closely examined during the first serious financial crisis of the hospital, the only result was the reiteration of the above rule with special emphasis on out-patients.

The great value to the hospital of many of the apothecaries who were governors has already been alluded to. The visiting apothecaries mentioned in the Account of the Erection of the Hospital (page 327), of whom Rand and Clarke were the most conspicuous for their services, all undertook much of the burden of the new hospital. The visiting apothecaries for many years gave a report to the weekly Board but the practice is not recorded after Treffrey was well established. The visits became irregular but were reinstituted on the instigation of the Board during Kelly's time. It is unlikely, however, that the visiting apothecaries' duties were allowed to slip. That is not until near the end of the century when, as stated earlier, the physicians assumed more of the administration.

The duties were, for example:

The druggs and medicines as bought be lodged in a convenient place under lock and key and that the weekly visiting apothecary be desired to keep one and another key to be kept by the rotating visitors to deliver at all times such quantityes of druggs and medicines as the house apothecary shall want and to take an account from him weekly how that quantity has been applyed till a more certain check can be agreed on.

At the same meeting (6 February 1733) the watch over dispensing was specifically stated in 'that the visiting weekly apothecary be desired to call every day or as often as he shall find it convenient and necessary to see that the dispensation and distributions are regular and this branch of physic well performed'.

Part of the work of the committee of apothecaries with regard to the shop's staff has been noted. Its first report 'for the better regulation of the shop' (I May 1734), contained the resolution:

that the apothecary of the house have the charge of all the druggs and that he keep a book mentioning when and what quantity he receives and another wherein he is to discharge himself of what he has disposed of and to whom and in what manner and that three apothecaries do audit his accounts the first week in every month.

This, suggesting more freedom for the apothecary, was not acted on and the Committee for Drugs and Medicines (see below) reaffirmed (28 February 1738 ) the earlier ruling of the Board. It being 


\section{John K. Crellin}

resolved that the visiting apothecaries do keep the keys of the store and see occasionally delivered out to the apothecary such druggs as he wants, that a fair account of such druggs as are brought into the stores and delivered out of it be faithfully kept by the clerk under the direction of [and vouched for by] the visiting apothecary.

It was the duty of the house apothecary to report to the Board a statement of the stores in the hospital.

The apothecaries also played a large part in the important business of purchasing drugs for the hospital. It was ordered by the Board on 21 December I 733,

that all the physicians, surgeons, apothecaries, chymists and druggists be a committee [Committee for Drugs and Medicines] to buy in the druggs for the life of the shop and they or any five of them whereof two to be apothecaries have power to sit ... and in the meantime that Mr. Dan. Graham, Mr. Rand and Mr. Clarke do buy in such druggs as there shall be immediate occasion for to be laid before the committee for their approbation as to goodness and price.

Despite the need to obtain the cheapest prices quality was always borne in mind. The first bill was paid (6 February 1 733) to Mr. Pincke, a chymist of Ludgate Hill. Pincke was a governor and this probably contributed to his virtual monopoly as a supplier of drugs (apart from small quantities from Apothecary Hall) during the first few years. Nevertheless this did not prevent his bills being diligently inspected by the Committee for Drugs and Medicines and the Board was sometimes pointed in its requests; once it 'ordered [10 March I 735] that Mr. Pincke's bill particularly with regard to the great quantity of spirits charged therein be referred to physicians, surgeons and apothecaries'. His bills eventually caused alarm and on the following 19 May it was stated that 'the chymicall and galenicall medicines be bought at Apothecary's Hall'. Pincke responded with a letter resulting in him remaining at least a supplier of crude drugs. An interesting purchase from him is recorded (I December I 736); it was 'resolved that two pounds weight more of rhubarb be sent from $\mathrm{Mr}$. Pincke for the use of the hospitall there being a likelihood of its growing dearer'.

The cost of preparations from Apothecary Hall caused more concern than Pincke's bills had done and Mr. Clarke's offer, in May I 737 'to supply [the] house with several medicines at a cheaper rate than they can be bought elsewhere', was accepted. The progressive chemist and druggist Joseph Clutton entered the scene in October 1738 when he told the Board that the 'articles [chymicall preparations] are charged considerably higher in price than they ought to be' and he offered 'to serve the hospital with the best medicines very much cheaper'. Previously unsuccessful attempts had been made to obtain discounts from Apothecary Hall. After Clutton's proposal, he and Pincke served the hospital jointly for three months before the general procedure, maintained during the 1 7oos, for supplying the hospital came into being.

An intimation of this procedure occurred on Io January 1738 when Treffrey was 'ordered to view the gum mentioned in the apothecaries' report of the 8th inst.'. The gum (guiacum) was purchased on Treffrey's recommendation9o lb. @ I $5 d$ per pound. But a month later, it was resolved 'that such druggs as are most in use in this hospital and proper to be kept in store shall for the 


\section{Eighteenth Century Pharmacy at St. George's Hospital, London}

future be bought in large quantities at the best hand'. The house apothecary was to make a list of the required drugs and these obtained by the visiting apothecaries. This method was further clarified at a Quarterly General Court (6 July 1739). The house apothecary was to give one month's notice to the Committee for Drugs and Medicines of impending drug sales and to procure samples. The visiting apothecaries were also requested to procure additional samples, both lots being displayed before the committee. It was then decided what purchases to make and the house apothecary arranged for the drugs to be brought to the hospital. The purchase was compared with the samples before being 'sealed up and put in store', and as previously indicated next supplied, when required, to the house apothecary by the visiting apothecaries. The exception to this was wines and spirits, which were the responsibility of the apothecary; he kept a check and sometimes records of the stock.

Drugs bought in bulk in the described manner, up to 1760 , included juniper berries, cortex peru, cantharides, manna, galbanum, guiacum, scammony, aloes, buckthorn juice, senna and cassia lignum. Drugs and medicines obtained in small quantities, when immediately required, were supplied early on by Pincke, Clutton and Clarke though other names soon appeared creating considerable competition. Apothecary Hall was deserted and in all thirty-six different wholesale concerns supplied the hospital to 1800 , both with bulk and smaller quantities of drugs. This includes a herbwoman, Mrs. Stone, and four other names-Charles Fraser, Sarah Jennings, John Butler and John Batchelor - supplying only 'physical herbs'. Bills, on account of the shop, were also regularly paid to the grocers, brewers and wine and spirit merchants in addition to those for items such as lard, white sheepskins (for plasters) and tow. Bills for grinding drugs also occasionally occur. Many of the suppliers were governors but there is no evidence that this led to any abuse.

No further references to purchasing occur until shortly after Browne was elected. It was ordered (6 March I 793) 'that the apothecary carry before the Board, the first Wednesday in every month an account of what medicines and other things are wanted'. Later (22 May I 799), another instance of the greater administrative control by the physicians is seen; 'no order for drugs nor any other article for the use of the apothecary's shop be given in future unless the specific order ... be signed by some one physician of the house' and the order then sanctioned by the weekly Board. Though not an entirely new departure from previous practice it was one less duty for the visiting apothecary. This was emphasized just after 1800 when the committee for examining drug samples comprised 'the physicians and such other governors as may be thought proper' - this time no specific mention of apothecaries, chymists and druggists.

This chapter in the history of pharmacy of St. George's illuminates the great care and diligence exercised in the early running of the department. Above all the rôle of the hospital apothecary, with his manifold and full-time duties was of paramount importance to the hospital. Also it was the manifold nature of his duties that made him distinct from his apothecary colleagues outside the hospital-a distinction still prevalent within present-day pharmacy. 


\section{John K. Crellin \\ ACKNOWLEDGMENT}

I wish to acknowledge my appreciation to the governors of St. George's Hospital for access to the hospital minutes.

\section{REFERENCES}

1. Peachey, G. G. History of St. George's Hospital. London, 1910-14, 32.

2. Ibid., p. 34.

3. Grain G R, H. S. 'The Apothecaries', Westminster Hosp. Sports and Social Club Quarterly Mag., III (No. 1), 1959, 3.

4. Cameron, H. C. Mr. Guy's Hospital, 1726-1948. London, 1954, 91.

5. Ghurgh, W. S. 'Our Hospital Pharmacopoeia and Apothecary's Shop', Saint Bart's Hosp. Rep., xxI, 1886, 23. 